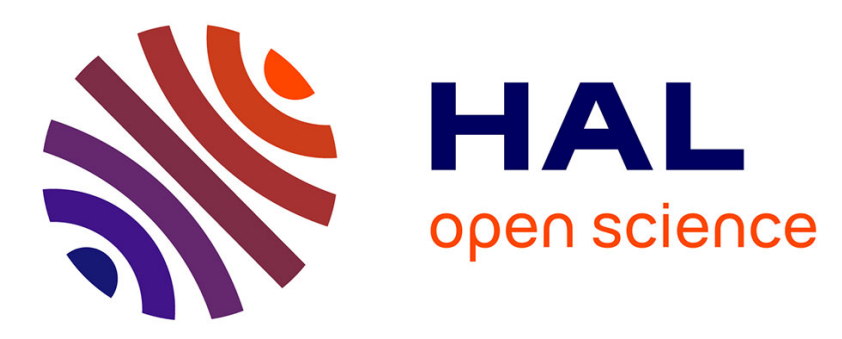

\title{
Modeling rapid flood propagation over natural terrains using a well-balanced scheme
}

Maricarmen Guerra, Rodrigo Cienfuegos, Cristian Escauriaza, Fabien Marche, José Daniel Galaz Mora

\section{- To cite this version:}

Maricarmen Guerra, Rodrigo Cienfuegos, Cristian Escauriaza, Fabien Marche, José Daniel Galaz Mora. Modeling rapid flood propagation over natural terrains using a well-balanced scheme. Journal of Hydraulic Research, 2014, 140 (7), 10.1061/(ASCE)HY.1943-7900.0000881 • hal-01094954

\section{HAL Id: hal-01094954 \\ https://hal.science/hal-01094954}

Submitted on 14 Dec 2014

HAL is a multi-disciplinary open access archive for the deposit and dissemination of scientific research documents, whether they are published or not. The documents may come from teaching and research institutions in France or abroad, or from public or private research centers.
L'archive ouverte pluridisciplinaire HAL, est destinée au dépôt et à la diffusion de documents scientifiques de niveau recherche, publiés ou non, émanant des établissements d'enseignement et de recherche français ou étrangers, des laboratoires publics ou privés. 


\title{
MODELING RAPID FLOOD PROPAGATION OVER NATURAL
}

\section{TERRAINS USING A WELL-BALANCED SCHEME}

\author{
Maricarmen Guerra ${ }^{1}$, \\ Rodrigo Cienfuegos ${ }^{2}$, \\ Cristian Escauriaza ${ }^{3}$, \\ Fabien Marche ${ }^{4}$, \\ and José Galaz ${ }^{5}$
}

\begin{abstract}
The consequences of rapid and extreme flooding events, such as tsunamis, riverine flooding and dam breaks show the necessity of developing efficient and accurate tools for studying these flow fields, and devise appropriate mitigation plans for threatened sites. Two-dimensional simulations of these flows can provide information about the temporal evolution of water depth and velocities, but the accurate prediction of the arrival time of the flood and the extent of the inundated areas still pose a significant challenge for numerical models of rapid flows over rough and variable topographies. Careful numerical treatments are required to reproduce the sudden changes in velocities and water depths, evolving under strong nonlinear conditions that often lead to breaking waves or bores. In addition, new controlled experiments of flood propagation in complex geometries are also needed to provide data for testing the models and evaluate their performance in more realistic conditions. In this work we implement a robust well-balanced numerical model to solve the nonlin-

\footnotetext{
${ }^{1}$ Departamento de Ingeniería Hidráulica y Ambiental, Pontificia Universidad Católica de Chile, Av. Vicuña Mackenna 4860, 7820436, Santiago, Chile. E-mail: mnguerra@uc.cl

${ }^{2}$ Departamento de Ingeniería Hidráulica y Ambiental, Pontificia Universidad Católica de Chile; Centro Nacional de Investigación para la Gestión Integrada de Desastres Naturales (CIGIDEN), Av. Vicuña Mackenna 4860, 7820436, Santiago, Chile. E-mail: racienfu@ing.puc.cl de Investigación para la Gestión Integrada de Desastres Naturales (CIGIDEN), Av. Vicuña Mackenna 4860, 7820436, Santiago, Chile. E-mail: cescauri@ing.puc.cl

${ }^{4}$ I3M, Université Montpellier 2, Montpellier, France. E-mail:Fabien.Marche@math.univ-montp2.fr

${ }^{5}$ Departamento de Ingeniería Hidráulica y Ambiental, Pontificia Universidad Católica de Chile, Av. Vicuña Mackenna 4860, 7820436, Santiago, Chile. E-mail: jdgalaz@uc.cl
}

${ }^{3}$ Departamento de Ingeniería Hidráulica y Ambiental, Pontificia Universidad Católica de Chile; Centro Nacional
\end{abstract}


ear shallow water equations (NSWE) in a non-orthogonal boundary-fitted curvilinear coordinate system. We show that the model is capable of computing flows over highly variable topographies, preserving the positivity of the water depth, and providing accurate predictions for wetting and drying processes. The model is validated against benchmark cases that consider the use of boundary-fitted discretizations of the computational domain. In addition, we perform a laboratory experiment of a rapid flood over a complex topography, measuring the propagation of a dam-break wave on a scaled physical model, registering time series of water depth in 19 cross-sections along the flow direction. We use the data from this experiment to test our numerical model, and compare our model performance with the numerical results of two other recognized NSWE models, showing that ours is a reliable tool for predicting efficiently and accurately extreme inundation events and long-wave propagation over complex topographies.

Keywords: Shallow water equations, shock capturing methods, well-balanced schemes, boundaryfitted curvilinear coordinates

\section{INTRODUCTION}

In recent years, a number of catastrophic events have involved rapid flooding over complex topography, such as tsunamis and river floods. In Chile, for example, several Glacial-lake outburst floods (GLOF) have occurred in the Colonia river, a tributary of the Baker river $\left(47^{\circ} 10^{\prime} \mathrm{S} ; 73^{\circ} 20^{\prime}\right.$ W), as a consequence of the Cachet-II lake outburst. In fact, two major events in 2008 generated an increase of the Baker river free surface elevation of above $4.5 \mathrm{~m}$ and a peak discharge over 3,000 $\mathrm{m}^{3} / \mathrm{s}$ (DGA Satellite monitoring station at Baker River, DGA-MOP, Chile), flooding large parts of the Colonia and Baker river valleys and putting at risk the town of Caleta Tortel, located at the mouth of the Baker river (Dussaillant et al. 2009). This event has repeated two times a year since 2008, which is likely linked to significant increments of temperature that have been registered on the entire watershed in the last years.

Recently, on February $27^{\text {th }}$ 2010, an 8.8 Mw earthquake occurred off the coast of south-central Chile (Fritz et al. 2011; Lay et al. 2010), generating a destructive tsunami that affected a significant portion of the coast, the Juan Fernández Archipiélago, and Easter Island, taking the lives of 124 
people. As a consequence of these events, local authorities and the central government are currently developing new hazards and risk plans in different coastal communities along Chile, which consider the investigation of the inundation extent and maximum water depth estimations, peak discharge and velocities, among other hydrodynamic variables for riverine floods and tsunamis.

In order to study the large and costly consequences of these major rapid flooding events, it is necessary to develop instruments that can be used to predict accurately and efficiently the flow velocities and water depths, and assess their associated hazards and risks. A good estimation of flow features such as run-up, affected areas, and arrival time of the peak flood will lead to define better the mitigation plans, early warning systems, and improve the preparedness of people when facing such catastrophic situations, incorporating the hydrodynamic forces into the design of coastal and riverine infrastructure (Federal Emergency Management Agency 2011; American Society of Civil Engineers 2006; Yeh 2006).

The Nonlinear Shallow Water Equations (NSWE) are usually employed in these cases to describe the flow dynamics, and model fairly long-waves in a homogeneous and incompressible fluid. They are obtained by vertically averaging the three-dimensional Navier-Stokes equations assuming a hydrostatic pressure distribution, resulting in a set of horizontal two-dimensional hyperbolic conservation laws that describe the evolution of the water depth and depth-averaged velocities (Cunge et al. 1980; Stoker 1992).

In the last decades, a significant number of numerical models have been developed to simulate these complex flows, employing finite-difference methods (e.g. Molls and Chaudry 1995; Molls and Zhao 2000), finite-element methods (e.g. Berger and Stockstill 1995; Tucciarelli and Termini 2000), or finite-volume methods (e.g. Valiani et al. 2002; Zhou et al. 2004; Loose et al. 2005). In the framework of finite volume methods, Godunov-type formulations have become very useful to solve the NSWE, since they can reproduce complex discontinuities such as shock-waves or wetdry interfaces by solving a Riemann problem at each cell interface of the discretized domain (Toro 2001; Leveque 2002).

Many environmental flows such as bore propagation (Hibberd and Peregrine 1979), tsunami 
inundations (Yeh 1991), or glacial lake outburst floods (Cenderelli and Wohl 2001), fall within this category of extreme flood events that can be represented by the NSWE. They are characterized by rapid wetting and drying over highly variable topographies, giving rise to complex unsteady free surface dynamics which pose a significant challenge for the numerical models. Numerical strategies for integrating the governing equations in these shallow extreme flows must also deal with complicated geometries and the highly complex dynamics of wave breaking and run-up. Similarly, the discretization of the boundaries of the physical domain may have a strong influence in the development of the flow dynamics, introducing errors or numerical instabilities if not carefully performed (Baghlani et al. 2008).

Motivated by these applications, in this investigation we develop an efficient numerical model to solve the two-dimensional dynamics of extreme flows over natural terrains. We extend the method of Marche et al. (2007), which has shown to resolve complex features of free-surface flows by implementing a well-balanced approach. Well-balanced schemes are specifically conceived to preserve local and global mass conservation to machine accuracy, maintaining also the steady and motionless states. To achieve this requirement, it is necessary to discretize carefully the friction and bed-slope source terms (see Greenberg and Leroux 1996; LeVeque 1998; Gallouet et al. 2003; Audusse et al. 2004; Liang and Marche 2009, for more details). We formulate and solve the governing equations in a non-orthogonal generalized curvilinear coordinate framework to model extreme flows propagation over natural terrains. We use a finite volume well-balanced approach based on a robust VFRoe-relaxation Riemann solver (Gallouet et al. 2003; Berthon and Marche 2008), calculating mass and momentum fluxes at cell interfaces and performing the hydrostatic reconstruction method proposed by Audusse et al. (2004). The source term that accounts for friction effects is treated with the semi-implicit fractional-step approach of Liang and Marche (2009). Validation of the new model is presented through the comparison with benchmark tests, which are specifically chosen to assess its ability to deal with wet-dry interfaces, complex geometries, shocks, friction and bathymetric source terms.

In addition, the future studies of these flows will require new experiments, representing the 
complex features of rapid flooding events over realistic arbitrary geometries, to test and improve the numerical models. In this investigation we also perform a dam-break experiment on a scaled physical model, representing the bed and banks of a mountain river. We register time-series of water depth, and then compare the results with simulations carried out with the new well-balanced numerical model, showing that it can capture the most relevant characteristics of the flow. Furthermore, in order to compare our model performance with previously validated numerical models, we simulated this experience using two well-known shock-capturing NSWE models, AnuGA (Mungkasi and Roberts 2013) and GeoClaw (Berger et al. 2011). From this comparison we can establish the improvement achieved by our numerical approach in terms of the overall agreement of the free surface variations in time, the estimation of the maximum amplitude of the propagated bore and its arrival time to different locations.

The paper is organized as follows: In section 2 we present the non-dimensional governing equations and the partial transformation to generalized non-orthogonal curvilinear coordinates that are employed in the model. The numerical scheme and the different algorithms used to integrate the NSWE are briefly described in section 3. Validation tests and comparisons of numerical simulations with benchmark cases and previously published experimental data are presented in section 4. In section 5 we describe new dam-break experiments conducted in the Hydraulic Laboratory of the Pontificia Universidad Católica de Chile, intended to further validate the model over a realistic and highly variable topographic configuration. Conclusions and future perspectives of this work are discussed in section 6.

\section{GOVERNING EQUATIONS}

The two-dimensional NSWE are a system of nonlinear partial differential equations representing the mass and momentum conservation laws, which were originally derived by Saint-Venant (1871). The fluid is assumed as incompressible and homogeneous, with hydrostatic pressure distribution. The shallow water or long-wave hypothesis considers negligible vertical velocities and depth-uniform horizontal velocities. Hence, the NSWE are often applied to river or nearshore flows where the characteristic horizontal wave-length is much longer that the characteristic water 
depth (see Cunge et al. 1980, for more details).

In what follows, we will work with a non-dimensionalized set of NSWE by choosing characteristic horizontal and vertical length-scales and a velocity scale $(\mathcal{L}, \mathcal{H}$, and $\mathcal{U}$ respectively). By defining the length and velocity scales of the flow, the time-scale is represented by $T=\mathcal{L} / \mathcal{U}$, and the dimensionless Froude number by $F r=\mathcal{U} / \sqrt{g \mathcal{H}}$, which quantifies the relative importance of inertial effects over gravity $(g)$. The dimensional variables, noted with a hat $(\widehat{ })$, are hereafter defined as $\widehat{x}=\mathcal{L} x, \widehat{y}=\mathcal{L} y, \widehat{z}=\mathcal{H} z, \widehat{h}=\mathcal{H} h, \widehat{u}=\mathcal{U} u, \widehat{v}=\mathcal{U} v$, and $\widehat{t}=T t$, where $\widehat{x}$ and $\widehat{y}$ represent the Cartesian directions, $\widehat{z}$ defines the bed elevation, $\widehat{h}$ is the water depth, $\widehat{u}$ and $\widehat{v}$ are the depth-averaged flow velocities in each Cartesian direction, and $\widehat{t}$ is the time. In order to reproduce better complex arbitrary geometries, we introduce a boundary-fitted curvilinear coordinate system in two dimensions denoted by the system $(\xi, \eta)$. Generalized curvilinear coordinates are chosen to follow the boundaries of the physical domain, adapting the grid to the geometrical details of the terrain. With this transformation we can have a better resolution in zones of interest and an accurate representation of the boundaries, resulting in an efficient discretization of the flow domain (Lackey and Sotiropoulos 2005; Liang et al. 2007; Baghlani et al. 2008).

The Cartesian NSWE can be partially transformed to this new coordinate system maintaining the hydrodynamic variables referenced to the Cartesian frame. This procedure is known as partial transformation and only modifies the mass and momentum fluxes of the governing equations. The full transformation would change the hydrodynamic variables vector, $Q=[h, h u, h v]^{T}$, to the velocity components in the $\xi$ and $\eta$ directions, using the so-called contravariant velocity components, and the derivatives in the convective terms would yield the well-known Christoffel symbols of the second kind (Ahn and Hosoda 2007). Therefore, considering only bed-slope and friction source terms, the non-dimensional NSWE can be written in curvilinear coordinates in the following form (Lackey and Sotiropoulos 2005),

$$
\frac{\partial Q}{\partial t}+J \frac{\partial F}{\partial \xi}+J \frac{\partial G}{\partial \eta}=S_{b}(Q)+S_{f}(Q)
$$

where $Q$ is the vector of hydrodynamic variables, $F$ and $G$ are the flux vectors expressed in terms 
of the new spatial coordinate system $\xi$ and $\eta$, respectively, and $S_{b}(Q)$ and $S_{f}(Q)$ are the source terms vectors. These vectors are given by the following expressions:

$$
\begin{gathered}
Q=\left(\begin{array}{c}
h \\
h u \\
h v
\end{array}\right), F=\frac{1}{J}\left(\begin{array}{c}
h U^{1} \\
u h U^{1}+\frac{1}{2 F r^{2}} h^{2} \xi_{x} \\
v h U^{1}+\frac{1}{2 F r^{2}} h^{2} \xi_{y}
\end{array}\right), G=\frac{1}{J}\left(\begin{array}{c}
h U^{2} \\
u h U^{2}+\frac{1}{2 F r^{2}} h^{2} \eta_{x} \\
v h U^{2}+\frac{1}{2 F r^{2}} h^{2} \eta_{y}
\end{array}\right), \\
S_{b}(Q)=\left(\begin{array}{c}
0 \\
-\frac{h}{F r^{2}}\left(z_{\xi} \xi_{x}+z_{\eta} \eta_{x}\right) \\
-\frac{h}{F r^{2}}\left(z_{\xi} \xi_{y}+z_{\eta} \eta_{y}\right)
\end{array}\right), S_{f}(Q)=\left(\begin{array}{c}
0 \\
-S_{f x} \\
-S_{f y}
\end{array}\right)
\end{gathered}
$$

where $h$ represents the water depth, $u$ and $v$ are the non-dimensional depth-averaged flow velocities in each Cartesian directions; $z$ defines the bed elevation, $z_{\xi}$ and $z_{\eta}$ define the local bed slope with respect to the transformed coordinate $\operatorname{system}(\xi, \eta)$ and $S_{f}$ represents the friction source term.

The additional terms that appear in the fluxes, $\xi_{x}, \xi_{y}, \eta_{x}$, and $\eta_{y}$ are the resulting metrics associated to the coordinate change, and $J=\xi_{x} \eta_{y}-\xi_{y} \eta_{x}$ is the Jacobian of the transformation, which will remain constant for a fixed grid. $U^{1}$ and $U^{2}$ are the contravariant velocity components, expressed as $U^{j}=u \epsilon_{x}+v \epsilon_{y}$ with $(j, \epsilon) \in\{(1, \xi),(2, \eta)\}$. The transformed system of equations is discretized on a rectangular and uniform grid in the transformed space $(\xi, \eta)$ using the finite volume method that is described in the next section.

\section{NUMERICAL SCHEME}

The curvilinear NSWE system given in Eq. (1) is integrated using a finite volume well-balanced scheme, coupled with a splitting strategy for the treatment of source terms (Liang and Marche 2009). We decompose the solution associated to the system of equations (1) at each time step by solving two systems, one associated to the NSWE with topography source terms and a second associated to the remaining friction terms. In the following subsections we describe the different steps of the algorithm, including the implementation of the boundary conditions, and the stability criterion of the numerical solution. 


\section{Solution of the NSWE with Topography Source Terms}

In this step we solve the following system associated to NSWE with topography source terms,

$$
\frac{\partial Q}{\partial t}+J \frac{\partial F}{\partial \xi}+J \frac{\partial G}{\partial \eta}=S_{b}(Q)
$$

We seek a numerical strategy that provides stable shock-capturing integration of system (3) with a precise control of the spurious oscillations induced by numerical dispersion. In addition, the scheme should be able to handle the complex interactions between flow and topography, including the preservation of motionless and steady states. We choose to adapt the robust second-order finite volume scheme introduced by Marche et al. 2007 to the non-orthogonal boundary-fitted coordinate framework.

Taking into account the new system of coordinates, the spatial discretization of Equation (3) can be recast under the following semi-discrete finite-volume formalism,

$$
\frac{d}{d t} Q_{i, j}+\frac{J_{i, j}}{\Delta \xi}\left(F_{i+\frac{1}{2}, j}^{*}-F_{i-\frac{1}{2}, j}^{*}\right)+\frac{J_{i, j}}{\Delta \eta}\left(G_{i, j+\frac{1}{2}}^{*}-G_{i, j-\frac{1}{2}}^{*}\right)=S_{b(i, j)}
$$

where $Q_{i, j}$ is the vector of cell-centered hydrodynamic variables, $J_{i, j}$ is the cell-centered Jacobian of the coordinate transformation, $F_{i \pm 1 / 2, j}^{*}$ and $G_{i, j \pm 1 / 2}^{*}$ correspond to the numerical flux functions through the $(i, j)$ cell interfaces, and $S_{b(i, j)}$ to the centered discretization of the bed-slope source term. We denote by $\Delta \xi$ and $\Delta \eta$ the cell sizes, and the interface between the $(i, j)^{t h}$ cell and the $(i+1, j)^{t h}$ by $\left(i+\frac{1}{2}, j\right)$, as depicted in Fig. 1 .

The computation of the numerical fluxes $F_{i \pm 1 / 2, j}^{*}$ and $G_{i, j \pm 1 / 2}^{*}$ is achieved using a robust VFRoerelaxation scheme proposed by Gallouet et al. (2003). To achieve a second order accurate scheme, we straightforwardly apply the MUSCL extrapolation proposed by Van Leer (1979). This technique considers that numerical fluxes are computed by linearly reconstructing the hydrodynamic variables, leading to more accurate reconstructed states at each side of the interface of every cell as shown in Fig. 1 (see Bouchut 2004, for details). In order to handle topographic variations and the requirement for the preservation of static flows, we also adapted the well-balancing discretiza- 
tion for the bed-slope term proposed by Audusse et al. (2004) to the boundary-fitted curvilinear coordinate system of equations. In this step of the algorithm we built a linear reconstruction of the topography considering the MUSCL reconstructed hydrodynamic variables as shown in Marche et al. (2007). Finally, the source term $S_{b}(Q)$ is estimated through the new reconstructed values of the fluxes. For a detailed description of the computation of the fluxes and the hydrodynamic variables the reader is referred to the work of Marche et al. (2007) and Berthon and Marche (2008).

\section{Solution of the Friction Source Terms}

The friction source term is incorporated using the splitting semi-implicit method proposed by Liang and Marche (2009). The corresponding ordinary differential equation of the splitting operation is defined as follows,

$$
\frac{d Q}{d t}=S_{f}
$$

where

$$
S_{f}=\left(0,-\tau_{f x},-\tau_{f y}\right)^{T}
$$

In this equation, the terms $\tau_{f x}$ and $\tau_{f y}$ are the non-dimensionalized bed shear-stresses for each cartesian direction. The magnitude of the bed shear stresses in each direction can be calculated as follows:

$$
\begin{aligned}
& \tau_{f x}=C_{f} u \sqrt{u^{2}+v^{2}} \\
& \tau_{f y}=C_{f} v \sqrt{u^{2}+v^{2}}
\end{aligned}
$$

where $C_{f}$ is a non-dimensionalized bed friction coefficient, which can be expressed using one of the standard existing approaches developed for uniform flows such as Manning or Chézy.

Following the algorithm developed by Liang and Marche (2009), equation (5) is integrated using an implicit scheme and a second-order Taylor series expansion. Note that an additional friction limitation may be locally added to prevent from unphysical flow reversing, due to large 
drag forces in vanishing depth areas, as mentioned by Burguete et al. (2008).

As far as time-discretization is concerned, we use a classical second-order Runge-Kutta scheme for each time-step in this splitting approach. In order to solve system shown in Eq. (1) at the boundaries of the computational domain, we have implemented and tested in the model three types of boundary conditions: i.) Transmissive or open boundary, allowing the information to freely leave the domain without propagating spurious information back to the domain; ii.) Solid wall or close boundary, that imposes no discharge through the boundary of the domain; and iii.) Absorbing/Generating boundary condition, which relies on the work of Sanders (2002) and Cienfuegos et al. (2007), which allow to prescribe inflow discharge or free surface information at the boundary, such as incoming waves or stage-discharge relationships, and freely evacuate back-traveling waves. Finally, the stability of the numerical model is controlled by the Courant-Friedrich-Lewy criterion (CFL) (Toro 2001).

\section{VALIDATION}

As previously explained, the numerical model in non-orthogonal generalized coordinates is based on the method of Marche et al. (2007), incorporating bed-friction with the splitting semiimplicit method of Liang and Marche (2009). Initially, we validated the model using various benchmark cases that are not shown herein, for rectangular domains employing discretizations in Cartesian coordinates. These first tests involved shock-capturing and moving shoreline problems, obtaining quantitatively accurate results in comparison with analytical solutions and laboratory data, which are the same cases previously studied by Marche et al. (2007). The following series of benchmark tests are intended to illustrate the improvements obtained when a boundary-fitted curvilinear discretization is used, and to prove the ability of the model to deal with complex geometries, bed-slope, and friction source terms.

\section{Dam-Break in a Convergent-Divergent Flume}

We test the numerical model with a dam-break induced flow in a convergent-divergent channel, performing simulations of two-dimensional flood waves studied experimentally by Bellos et al. (1992). The channel is $21.2 \mathrm{~m}$ long and has a rectangular cross-section of variable width. At a 
distance of $5 \mathrm{~m}$ downstream from the beginning of the flume, there is a smooth curved contraction and expansion of $0.6 \mathrm{~m}$ of minimum width, the flume has a constant bed-slope that can be changed and ranges between $\pm 1 \%$. For a detailed description of the domain the reader is referred to the work of Bellos et al. (1992).

The simulation of the experiment was carried out using a non-uniform boundary-fitted mesh of $241 \times 41$ cells and the channel was assumed to have a mild bed-slope, $S_{0}=0.002$, and a Manning friction coefficient $n=0.012$ consistent with the recommendations of Bellos et al. (1992). The dam is located at the end of the contraction, at a distance of $8.5 \mathrm{~m}$ from the upstream boundary of the flume. Initial conditions consist of a water depth upstream of the dam of $0.30 \mathrm{~m}$, null flow velocities, and dry terrain downstream of the dam. A no-flow boundary condition was imposed at the sidewalls and at the upstream boundary of the flume. At the downstream end of the channel an open boundary condition is applied to allow all the information to exit the domain without propagating back and perturbing the numerical solution. The simulations were carried out for 70 s using a CFL number equal to 0.9 in order to ensure numerical stability during the computations. The geometry of the channel, dimensions and location of measurement points studied by Bellos et al. (1992) along with the computational mesh are shown in Fig. 2.

The results show that dam-break phenomena is correctly captured by the numerical model as observed in Fig. 3. At the breaking, the shock wave spreads through the expansion and propagates downstream inundating the dry bottom. A rarefaction wave propagates upstream decreasing the water depth, which is then reflected at the upstream closed boundary of the flume. Then, the water depth in the flume starts decreasing, reaching a minimum of $0.014 \mathrm{~m}$ after $70 \mathrm{~s}$. From the images depicted in Fig. 3, it can be seen that computed water depths and arrival times of the front are in excellent agreement with experimental data for all the studied measurement points, confirming the abilities of the model to capture shocks and deal with wet-dry cells and source terms over a curvilinear geometry. 


\section{Dam-Break over a closed basin with steep topography and friction}

An important characteristic of the model is its capability of handling frictional source terms in the numerical solution of the NSWE, especially in situations where the flow is shallow or when the process of wave run-up/run-down is important. Here we test the numerical model with the flood produced by a dam-break over a closed channel with three conical obstacles. This test was first proposed by Kawahara and Umetsu (1986) and subsequently used by many researchers (e.g. Brufau et al. 2002; Brufau and García-Navarro 2003; Gallardo et al. 2007; Nikolos and Delis 2009) to assess the ability of numerical models to deal with steep bed-slopes and friction source terms, wetting/drying proceses, and test local and global mass conservation.

The basin is $70 \mathrm{~m}$ long in the streamwise $x$ direction and $30 \mathrm{~m}$ wide in the cross-stream or $y$ direction. The bed topography is defined by the following equation,

$$
z(x, y)=\max \left[\begin{array}{c}
0 \\
1-0.1 \cdot \sqrt{(x-30)^{2}+(y-22.5)^{2}} \\
1-0.1 \cdot \sqrt{(x-30)^{2}+(y-7.5)^{2}} \\
2.8-0.28 \cdot \sqrt{(x-47.5)^{2}+(y-15)^{2}}
\end{array}\right]
$$

Initial conditions consist of a motionless free surface elevation upstream of the dam location (at $x=16 \mathrm{~m}$ ) equal to $1.85 \mathrm{~m}$, and a dry bottom bed downstream. The simulation was performed employing a $101 \times 101$ uniform mesh using the suggested Manning coefficient of $n=0.018$, and no-flow boundary conditions were applied to all the sidewalls of the basin. Computations were carried out for $400 \mathrm{~s}$ in order to achieve steady state as shown in previous investigations (Nikolos and Delis 2009), using a CFL number equal to 0.9 to ensure the stability of the model during the computations.

Evolution of the free surface is shown in Fig. 4. After the dam-break, the flood wave wets the small obstacles and a reflected wave is propagated back to the upstream boundary. At the same time, the front passes through the small obstacles and runs up and down over the larger obstacle, 
which is partially dry. Later, the wetting front separates and symmetrically goes around the larger mound as it crosses back at the middle of the channel downstream from the larger conical obstacle. Finally, the wave hits the downstream solid boundary and is reflected back to the obstacles. The motion decays in time as a consequence of the friction force and after approximately $400 \mathrm{~s}$, the steady state is reached leaving the three obstacles partially dry. These results agree well with those obtained by Gallardo et al. (2007) and Nikolos and Delis (2009), and illustrate the ability of the model to represent the interaction between dry and wet cells with high accuracy over a steep and frictional topography. Results also demonstrate that global mass conservation was achieved during the entire computation. Therefore, the robustness and stability of the friction scheme in conjunction with the well-balancing properties of the solution of the hyperbolic system are validated.

\section{EXPERIMENTAL DAM-BREAK OVER COMPLEX TERRAIN AND NUMERICAL SIMULATION}

With the purpose of testing the numerical model, we carry out an experiment for the propagation of a dam-break wave generated by the rapid emptying of a reservoir over a scaled physical model of a river. The experiments were conducted in the Hydraulic Laboratory of the Pontificia Universidad Católica de Chile. In this section we present the details of the experiment, and the comparison between experimental results and numerical solutions obtained with our model and with two recognized NSWE models: AnuGA (Roberts et al. 2010; Mungkasi and Roberts 2013) and GeoClaw (Clawpack Development Team 2013; Berger et al. 2011), showing the capacity of the models to handle highly demanding natural conditions analogous to the propagation of a tsunami wave over varying topography.

\section{Experimental Set-up}

Dam-break experiments were conducted in a physical model of a river consisting of a narrow and steep valley with complex topography presented in Fig. 5(a). The model was built using a geometrical scale equal to 1:60 and Froude similarity. The entire river reach is $14.6 \mathrm{~m}$ long and has a maximum width of $4.5 \mathrm{~m}$. It starts with a narrow and curved zone with an average adverse bed-slope of nearly $-4.5 \%$, then it becomes wider towards its downstream end. The average bed- 
slope over the river reach considered in the experiments is $-1.5 \%$. A longitudinal profile of the river reach along with the location of the measurements points is shown in Fig. 5(b). The river bed was built with a uniform concrete mix with fine gravel, which yields a roughness characterized by a Manning coefficient of $n=0.014$.

Upstream of the river reach, there is a reservoir and a wooden gate that holds a fixed volume of water equal to $2.17 \mathrm{~m}^{3}$. The experiment we carry out consists of a sudden lift of the reservoir gate to release the water into a quiescent free surface downstream. A bore wave is then produced and propagated to the end of the river reach. The free surface evolution within the scaled-model is recorded during $60 \mathrm{~s}$. At the reservoir, free surface elevation is set at $0.85 \mathrm{~m}$, while at the river it is set at $0.56 \mathrm{~m}$ as shown in Fig. 5(b). Free surface variations are recorded at nineteen points in the river reach and at the reservoir as depicted in Fig. 5(b).

At the reservoir, free surface variations were measured using a KPSI brand pressure transducer recording voltage at $100 \mathrm{~Hz}$. The accuracy of this instrument is $\pm 1 \%$. It was calibrated such that $1 \mathrm{~V}$ equals $1 \mathrm{~m}$ of water column. At downstream cross-sections, free surface variations over the mean water level were measured using wave DHI resistive gauges, which were located at the thalweg of the studied cross sections. Each gauge records voltage data at $100 \mathrm{~Hz}$, the accuracy of these gauges is $\pm 1.5 \mathrm{~mm}$ and the zero drift is $\pm 5 \%$, depending on the water temperature.

For the experiments, we use four resistive gauges, i.e. only four points could be measured at each run. Thus, five set of experiments with different gauge positions, are performed in order to cover the nineteen considered sections. As a verification of the repetability of the data, three repetitions were performed at each gauge location, maintaining the position of the pressure sensor in the reservoir in order to use it as a reference to synchronize the time series.

\section{Numerical Simulation}

The digitized bathymetry of the physical model is constructed from 39 measured cross sections within the river reach. Then, the bathymetric data together with the reservoir geometry is interpolated using a cubic spline method to create a boundary-fitted computational domain, which correctly represents the bathymetric features of the river reach and its geometry. The physical 
model is discretized into $130 \times 30$ cells of variable size, covering an area of $16 \times 4.5 \mathrm{~m}^{2}$. The mesh used in the simulations and the digitized bathymetry are shown in Fig. 6. As initial conditions, free surface elevations at the reservoir and the river are set to $0.85 \mathrm{~m}$, and $0.56 \mathrm{~m}$, respectively. Zero velocities over the entire domain are considered at $t=0$. The open boundary condition is used at the downstream end of the river reach and close boundary conditions are applied to the sides of the computational domain. CFL condition is set to 0.9 in order to ensure the numerical stability of the simulations. The gate is instantly removed at $t=0$ and the wave propagates downstream as seen in the experiments.

\section{Results}

The numerical model is able to simulate the dam-break event and the propagation of the bore wave over the river reach. Fig. 7 illustrates the propagation process showing 4 snapshots of the numerical computation, where the blue color represents the wet surface. As depicted in these figures, the bore propagates downstream of the river reach through the narrow and steep valley. It takes approximately 10 seconds to the bore wave to reach the end of the river reach $(\approx 14 \mathrm{~m})$. The entire flood wave propagates downstream along the complex geometry of the physical model, flooding and drying cells, and reaches a steady state after nearly 60 seconds. Fig. 8 shows the velocity vectors field 10 seconds after the gate opening; flow features observed in the laboratory experiments, such as recirculation and reflection due to topographical obstacles are observed in these numerical results. The main aspects of the rapidly varying flow measured in the experiments are thus reproduced by the numerical model.

Evolution of the bore wave is studied and compared to experimental data through time series of the computed free surface dynamics at the same locations measured in the experiments. Additionally, we have carried out numerical simulations using similar NSWE numerical models in order to assess and compare our model accuracy for similar discretization settings. The chosen numerical models are AnuGA (Roberts et al. 2010; Mungkasi and Roberts 2013) and GeoClaw (Clawpack Development Team 2013; Berger et al. 2011). Both models solve the NSWE using a well-balanced shock-capturing finite volume method, mainly differing in the discretization of the 
domain; AnuGA model uses non-structured meshes, while GeoClaw uses an adaptive meshing approach. In order to define comparable grids for both simulations, we prepared meshes with a similar discretization sizes. For the AnuGA model, we defined a mesh of 4026 triangular elements. GeoClaw model uses an adaptive mesh configuration that varies the distribution of element size with time, defining areas of refinement when needed. For this particular case, the refinement zone was controlled in order to mantain a number of grid nodes similar to our model and to AnuGA. Figures showing the defined grids for AnuGA and GeoClaw along with the configuration for both simulations are presented in Appendix I.

Comparisons between measured and computed time series of the free surface evolution for the three models are presented in Fig. 9. Our analysis shows that the main features of the process, i.e. the arrival times, peak amplitudes and recession curves, are well reproduced by our numerical model and by GeoClaw. AnuGA results seem to be accurate in representing maximum amplitude, but for this particular case, the model overestimates the final free surface elevation.

Based on the results obtained in the simulations, we establish three quantities related to the inundation and propagation process that are studied, namely the overall agreement of the free surface elevation on time, the maximum amplitude of the bore at each measurement location and the arrival time of the wave front. For each of these variables, mean relative errors to the measurements were calculated at gauge locations; these relative errors are defined as follows:

\section{Relative root mean square error (RRMSE)}

A root mean square error is used to compare the experimental and numerical free surface elevation at each location and at the same time to highlight the locations were the larger differences were found. The relative root mean square error for a location $k$, and the average relative root mean square error considering all locations are defined respectively as:

$$
\operatorname{RRMSE}_{k}^{2}=\frac{1}{T} \int_{0}^{T}\left(\frac{\eta_{m}^{k}(t)-\eta_{n}^{k}(t)}{\eta_{m}^{k}(t)}\right)^{2} d t
$$




$$
R R M S E=\left(\frac{1}{M} \sum_{k=1}^{n} R R M S E_{k}^{2}\right)^{1 / 2}
$$

where $T$ is the period of time considered in measurements and in simularions (60 s); $M$ is the number of measurement points, and $\eta_{m}^{k}$ and $\eta_{n}^{k}$ are the measured and numerical free surface elevation at each $k$ location respectively.

\section{Maximum amplitude of the wave}

The maximum amplitude of the bore is an important flood variable since it is related with the destructive potential of the wave. This variable is defined as the difference between the maximun and the initial free surface elevation at the river reach. The mean relative error between experimental data and numerical results is estimated as follows:

$$
\Delta H_{r}=\frac{1}{M} \sum_{k=1}^{M}\left|\frac{H\left(\eta_{m}^{k}\right)-H\left(\eta_{n}^{k}\right)}{H\left(\eta_{m}^{k}\right)}\right|
$$

\section{Arrival time}

The arrival time of the wave is an interesting parameter for defining evacuation plans as it indicates the available time to leave flood-prone areas and it is also a proxy for the celerity of the bore. The arrival time of at a location $k$ is defined as the first instant where the signal surpasses the initial value by a certain threshold, which is defined here as $1 \mathrm{~mm}$. The mean relative error of this variable over all the measuring sections is defined as:

$$
\Delta T^{a}=\frac{1}{M} \sum_{k=1}^{M}\left|\frac{T^{a}\left(\eta_{m}^{k}\right)-T^{a}\left(\eta_{n}^{k}\right)}{T^{a}\left(\eta_{m}^{k}\right)}\right|
$$

The calculated mean relative errors for each model are summarized in Fig. 10. The RRMSE for the three models shows a very good overall agreement between measurements and numerical predictions, with a $1.7 \%$ relative error for our model and a $2.1 \%$ relative error for AnuGA and GeoClaw, which is an acceptable error considering how demanding the experiment is. For our model, the highest relative errors are found in the gauges located upstream, near the gate. 
It is found that in average, the maximum amplitude is underestimated by all models, being the variable with the higher relative error. However, in terms of arrival times of the wave front, predicted results are in excellent agreement with observations (less than 5\% mean relative error for our model). Main differences were found in the first gauges closer to the reservoir with maximum local errors reaching 10\%. These differences might be explained by the opening mechanism of the gate, which is frictionless and instantaneous in the simulation, but performed in a finite time in the experiments, where vertical velocities might also be generated and interfere with the dynamics of the wave downstream, thus increasing the maximum amplitude of the wave.

Summarizing, the results from our model show that it can correctly capture the time evolution of the free surface elevation, the arrival time of the bore and its maximum amplitude. For this singular case, our simulations show a decrease in the studied relative errors when comparing to the results of previously validated numerical models when a similar discretization setting of the domain is used.

\section{CONCLUSIONS}

In this investigation we have developed and validated a finite-volume numerical model to simulate extreme flows and rapid flooding over natural terrains and complex geometries. The numerical scheme successfully reproduces the flow hydrodynamics over rough and highly variable topographies, incorporating an accurate and robust treatment of bore dissipation and wet and dry process. The method is based on algorithms proposed by Marche et al. (2007), and adapted here to solve the bed-slope source term and to incorporate friction by using the splitting semi-implicit scheme developed by Liang and Marche (2009). An important advantage of this model is the simplicity and low cost of its implementation, yielding accurate results using coarse computational grids.

Two benchmark test cases are considered to illustrate the capabilities of our new model. Test cases involve the use of boundary-fitted grids, with frictional and varying bathymetry, and dambreak floods. The use of boundary fitted grids is shown for the case of the dam-break in a converging-diverging flume (Bellos et al. 1992). Numerical results are in excellent agreement with experimental data obtained by Bellos et al. (1992), showing the ability of the model to deal with 
a complex geometry and a rapidly varying flow. The process of run-up and run-down, and wetting and drying of the terrain as the wave propagates are reproduced in the numerical simulations of the benchmark cases analyzed in this investigation. This case also illustrates the stability and the well-balanced property of our model, since steady state is correctly reached due to frictional effects.

We report new experimental data for a dam-break wave propagating over the scaled physical model of a river reach with narrow and steep valleys. This experiment was specially designed to test the numerical model and to evaluate its ability for representing extreme and rapid flooding over natural conditions. For this case, we have also compared our results with those from two other NSWE numerical models, showing a better relative performance by our model in terms of the studied hydrodynamic variables when similar computational discretizations are employed.

The results reported in this research confirm that our numerical model is a robust and powerful tool that can be used to simulate high-volume flash-floods and significant inundation over dry terrain under realistic conditions, giving accurate results in terms of water depth evolution, discharge and inundated area. The model performance shows that it can become a useful tool for evaluating extreme and rapid flood events over complex bathymetries, and to assess their hazards in terms of inundation extent and depth, depth-averaged velocities, arrival time of peak discharge, etc. We expect that the model will be used as an instrument to develop new inundation hazard maps in coastal and riverine areas.

Future research using the model developed in this investigation will focus on the study of complex engineering and geophysical flows. Large-scale coastal flows, such as tsunami propagations (Yamazaki and Cheung 2011), will also be studied by incorporating the Coriolis effect into the model. Also, advanced sediment transport and morphodynamic models (Cao et al. 2004; Vasquez et al. 2008) will be added to the basic equations of the flow to study erosion and sedimentation processes in fluvial and coastal environments. Finally, this model will be employed to investigate density-coupled flows, incorporating the transport of active and passive contaminants in rivers and estuaries (Loose et al. 2005). 


\section{APPENDIX I.}

In this section we present additional information about the configuration used for the numerical simulations of the Dam-break over a physical model using AnuGA and GeoClaw numerical models. Fig. 11 present the mesh configuration for each model; Fig. 11(a) presents the triangular mesh of 4026 required by the AnuGA model and Fig. 11(b) presents the initial adaptive mesh used for the simulation with GeoClaw. The element size distribution of the AnuGa and of our model considered approximately a $60 \%$ of the elements under $100 \mathrm{~cm}^{2}$ in size, being both distributions comparable. For the simulation using GeoClaw, the time evolution of the distribution of elements was controled in order to maintain the number of the finer elements aroud 4000, which are 69.4 $\mathrm{cm}^{2}$ in size. For both models, CFL number was set equal to 0.95 in order to achieve numerical stability. 


\section{APPENDIX I. REFERENCES}

Ahn, T. and Hosoda, T. (2007). "Depth-Averaged model of open-channel flows over an arbitrary 3D surface and its applications to analysis of water surface profile." J. Hydraul. Eng. ASCE, 133, $350-360$.

American Society of Civil Engineers (2006). Flood Resistant Design and Construction. ASCE.

Audusse, E., Bouchut, F., Bristeau, M., Klein, R., and Benoit, P. (2004). "A fast and stable wellbalance scheme with hysdrostatic reconstruction for shallow water flows." SIAM J. Comput. Sci., 25(6), 2050-2065.

Baghlani, A., Talebbeydokhti, N., and M.J., A. (2008). "A shock-capturing model based on fluxvector splitting method in boundary-fitted curvilinear coordinates." Appl. Math. Model., 32, 249-266.

Bellos, C., Soulis, J., and Sakkas, J. (1992). "Experimental investigation of two-dimensional dambreak induced flows." J. of Hydraul. Res., 30, 47-63.

Berger, M., George, D., LeVeque, R., and Mandli, K. (2011). “The geoclaw software for depthaveraged flows with adaptive refinement.” Adv. Water Resour., 34(9), 1195 - 1206.

Berger, R. and Stockstill, R. (1995). "Finite-element model for high-velocity channels.” J. Hydraul. Eng. ASCE, 121, 225-252.

Berthon, C. and Marche, F. (2008). "A positive preserving high order VFRoe scheme for shallow water equations: A class of relaxation schemes." SIAM J. Sci. Comput., 30, 2587-2612.

Bouchut, F. (2004). Nonlinear stability of Finite Volume Methods for Hyperbolic Conservation Laws. Birkhäuser.

Brufau, P. and García-Navarro, P. (2003). "Unsteady free surface flow simulation over complex topography with multidimensional upwind technique.” J. Comput. Phys., 186, 503-526.

Brufau, P., Vásquez-Cendón, M., and García-Navarro, P. (2002). “A numerical model for the flooding and drying of irregular domain.” Int. J. Numer. Methods in Fluids, 39, 247-275.

Burguete, J., García-Navarro, P., and Murillo, J. (2008). "Friction term discretization and limitation to preserve stability and conservation in the 1D shallow-water model: Application to unsteady 
irrigation and river flow." Int. J. Numer. Methods in Fluids, 58, 403-425.

Cao, Z., Pender, G., Wallis, S., and Carling, P. (2004). “Computational dam-break hydraulics over erodible sediment bed." J. Hydraul. Eng. ASCE, 130, 689-703.

Cenderelli, D. and Wohl, E. (2001). "Peak discharge estimates of glacial-lake outburst floods and normal climatic floods in the Mount Everest region, Nepal.” Geomorphol., 40, 57 - 90.

Cienfuegos, R., Barthelemy, E., and Bonneton, P. (2007). "A fourth order compact finite volume scheme for fully nonlinear and weakly dispersive Boussinesq-type equations - Part II : Boundary Conditions and validation..” Int. J. Num. Methods in Fluids, 53, 1423-1455.

Clawpack Development Team (2013). "Clawpack software, <http://www.clawpack.org >. Version 4.6.3.

Cunge, J., Holly, F., and Verwey, A. (1980). Practical Aspects of Computational River Hydraulics. Pitman Publishing Limited.

Dussaillant, A., Benito, G., Buytaert, W., Carling, P., Meier, C., and Espinoza, F. (2009). "Repeated glacial-lake outburst floods in Patagonia: an increasing hazard?.” Nat. Hazards, 54, 469-481.

Federal Emergency Management Agency (2011). Coastal Construction Manual: Principles and Practices of Planning, Siting, Designing, Constructing, and Maintaining Residential Buildings in Coastal Areas. FEMA, 4th edition.

Fritz, H., Petroff, C., Catalan, P., Cienfuegos, R., Winckler, P., Kalligeris, N., Weiss, R., Barrientos, S., Meneses, G., Valderas-Bermejo, C., Ebeling, C., Papadopoulos, A., Contreras, M., Almar, R., Dominguez, J., and Synolakis, C. (2011). "Field survey of the 27 february 2010 Chile tsunami." Pure App. Geoph., 168, 1989-2010.

Gallardo, C., Parés, M., and Castro, M. (2007). “On a well-balanced higher-order finite volume scheme for shallow water equations with topography and dry areas." J. Comput. Phys, 227, $574-601$.

Gallouet, T., Herard, J.-M., and Seguin, N. (2003). "Some approximate Godunov scheme to compute shallow-water equations with topography." Comput. Fluids, 32, 479-513.

Greenberg, J. and Leroux, A. (1996). "A well-balanced scheme for the numerical processing of 
source terms in hyperbolic equations." SIAM J. Numer. Anal., 33(1), 1-16.

Hibberd, S. and Peregrine, D. (1979). "Surf and run-up on a beach: a uniform bore.” J. Fluid Mech., 95, 323-345.

Kawahara, M. and Umetsu, T. (1986). "Finite element method for moving boundary problems in river flow." Int. J. Num. Meth. Fluids, 6, 365-386.

Lackey, T. and Sotiropoulos, F. (2005). "Role of artificial dissipation scaling and multigrid acceleration in numerical solution of the depth-averaged free-surface flow equations." J. Hydraul. Eng. ASCE, 131, 476-487.

Lay, L., Ammon, C., Kanamori, H., Koper, K., Sufri, O., and Hutko, A. (2010). "Teleseismic inversion for rupture process of the 27 february 2010 chile (mw 8.8) earthquake." Geophys. Res. Lett., 37.

LeVeque, R. (1998). "Balancing source terms and flux gradients in high-resolution godunov methods: the quasi-steady wave-propagation algorithm." J. of Comput. Phys., 146(1), 346-365.

Leveque, R. (2002). Finite Volumen Methods for Hyperbolic Problems. Cambridge University Press.

Liang, D., Lin, B., and Falconer, R. (2007). “A boundary-fitted numerical model for flood routing with shock-capturing capability." J. Hydrol., 332, 477-486.

Liang, Q. and Marche, F. (2009). "Numerical resolution of well-balanced shallow water equations with complex source terms." Adv. Water Resour., 32, 873-884.

Loose, B., Niño, Y., and Escauriaza, C. (2005). "Finite volume modeling of variable density shallow-water flow equations for a well-mixed estuary: application to the rio Maipo estuary in central Chile.” J. Hydraul. Res., 43, 339-350.

Marche, F., Bonneton, P., Fabrie, P., and Seguin, N. (2007). "Evaluation of well-balance borecapturing schemes for 2D wetting and drying processes." Int. J. Numer. Methods in Fluids, 53, 867-894.

Molls, T. and Chaudry, D. (1995). "Depth-averaged open-channel flow model.” J. Hydraul. Eng. ASCE, 121, 453-465. 
Molls, T. and Zhao, G. (2000). "Depth-averaged simulation of supercritical flow in channel with wavy sidewall." J. Hydraul. Eng. ASCE, 126, 437-444.

Mungkasi, S. and Roberts, S. G. (2013). "Validation of anuga hydraulic model using exact solutions to shallow water wave problems." J. of Phys.

Nikolos, I. and Delis, A. (2009). "An unstructures node-centered finite volume scheme for shallow water flows with wet/dry fronts over complex topography." Comput. Methods Appl. Mech. Eng., $198,3723-3750$.

Roberts, S., Nielsen, O., Duncan, G., and Sexton, J. (2010). AnuGA User Manual. Australian National University and Geoscience Australia.

Saint-Venant, A. (1871). "Théorie du mouvement non permanent des eaux, avec application aux crues des rivières et à l'introduction des marées dans leur lit." C.R.Acad.Sc.Paris, 73, 147-154.

Sanders, B. (2002). "Non-reflecting boundary flux function for finite volume shallow water models." Adv. Water Resour., 25, 195-202.

Stoker, J. (1992). Water Waves, The Mathematical Theory with Applications. John Wiley and Sons, Inc.

Toro, E. (2001). Shock-Capturing Methods for Free-Surface Shallow Flows. John Wiley and Sons, Inc.

Tucciarelli, T. and Termini, D. (2000). "Finite-element modeling of floodplain flow." J. Hydraul. Eng. ASCE, 126, 416-424.

Valiani, A., Caleffi, V., and Zanni, A. (2002). "Case study: Malpasset dam-break simulation using a two-dimensional finite volume method." J. Hydraul. Eng. ASCE, 128, 460-472.

Van Leer, B. (1979). "Toward the ultimate conservative difference scheme V. A second order sequel to Godunov's method." J. Comput. Phys., 32, 101-136.

Vasquez, J., Steffler, P., and Millar, R. (2008). "Modeling bed changes in meandering rivers using triangular finite elements." J. Hydraul. Eng. ASCE, 134, 1348-1352.

Yamazaki, Y. and Cheung, K. (2011). "Shelf resonance and impact of near field tsunami generated by the 2010 Chile earthquake." Geophys. Res. Lett., 38. 
Yeh, H. (1991). “Tsunami bore runup.” Nat. Hazards, 4, 209-220.

Yeh, H. (2006). "Maximum fluid forces in the tsunami runup zone.” J. Waterway, Port, Coastal, Ocean Eng., 132, 496-500.

Zhou, J., Causon, D., Mingham, C., and Ingram, D. (2004). "Numerical prediction of dam-break flows in general geometries with complex topography." J. Hydraul. Eng. ASCE, 130, 332-340. 


\section{List of Figures}

1 Discretization cell and numerical fluxes. L and $\mathrm{R}$ denote the left and right boundaries of the cell, - and + signs are the left and right sides of the cell interface. . . . 29

2 Dam-Break in a convergent-divergent flume: Geometry of the channel, boundaryfitted grid, bathymetry and measurement points (black dots) . . . . . . . . . . . . . 29

3 Dam-Break in a convergent-divergent flume: Water depth time series at measurement points. (a) $x=4.0 \mathrm{~m}$, (b) $\mathrm{x}=8.5^{-} \mathrm{m}$, (c) $\mathrm{x}=8.5^{+} \mathrm{m}$, (d) $\mathrm{x}=13.5 \mathrm{~m} \ldots 30$

4 Dam-Break over a closed basin: Free surface elevation. (a) $t=2 \mathrm{~s}$, (b) $t=12 \mathrm{~s}$, (c)

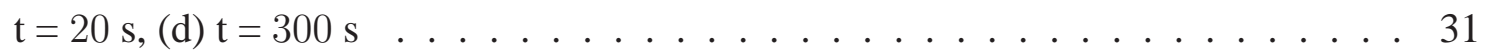

5 Dam break Experience: (a) Physical model and measurement instruments, upstream view, (b) Longitudinal profile of the river reach bottom elevation, initial conditions and measurement points . . . . . . . . . . . . . . 32

6 Numerical Model of dam break experience: Digital bathymetry of the physical domain and curvilinear mesh of the physical model of $130 \times 30$ cells . . . . . . . 33

$7 \quad$ Numerical model of dam-break experience: Flood extension at different times (a) Initial condition, (b) $\mathrm{t}=4.4 \mathrm{~s},(\mathrm{c}) \mathrm{t}=20 \mathrm{~s},(\mathrm{~d}) \mathrm{t}=60 \mathrm{~s} \ldots \ldots . \ldots . \ldots 33$

8 Numerical model of dam-break experience: Velocity vectors for the propagation of the flooding wave over the river at $\mathrm{t}=10 \mathrm{~s} \ldots \ldots \ldots$

9 Numerical model of dam-break experience: Comparison between measured and predicted free surface elevation at different locations, (a) Reservoir, (b) Gauge location 24, (c) Gauge location 20, (d) Gauge location 12. In all figures, the dotted black line represents the experiments and the solid lines represent the numerical results of our model, GeoClaw, AnuGA . . . . . . . . . . . . . . . . 35

10 Summary of mean relative errors between experiments and numerical results for each NSWE model. RRMSE: Relative root mean square error between experimental and numerical free surface elevation. $\Delta H_{r}$ Mean relative error in the maximum amplitude of the bore. $\Delta T_{r}^{a}$ : Mean relative error in the arrival time of the bore. . . 36 
11 Physical model discretization grids: (a) Triangular mesh of 4060 elements for AnuGA model, (b) Initial adaptive mesh with three levels of refinement for Geo-

Claw model . . . . . . . . . . . . . . . . . . . 36 


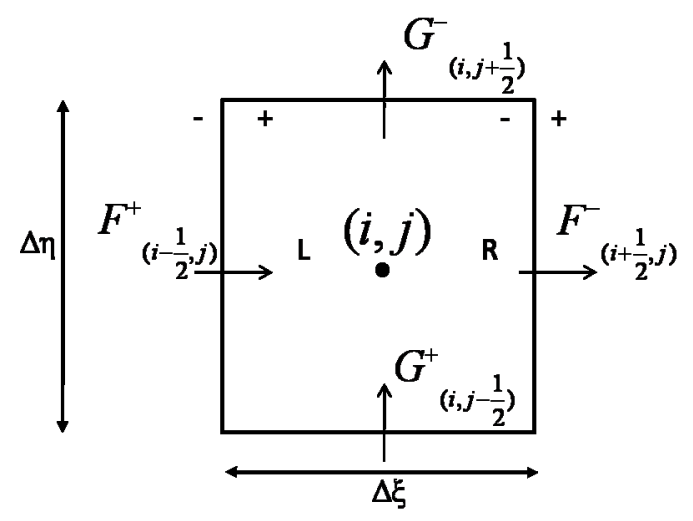

FIG. 1. Discretization cell and numerical fluxes. $L$ and $R$ denote the left and right boundaries of the cell, - and + signs are the left and right sides of the cell interface.

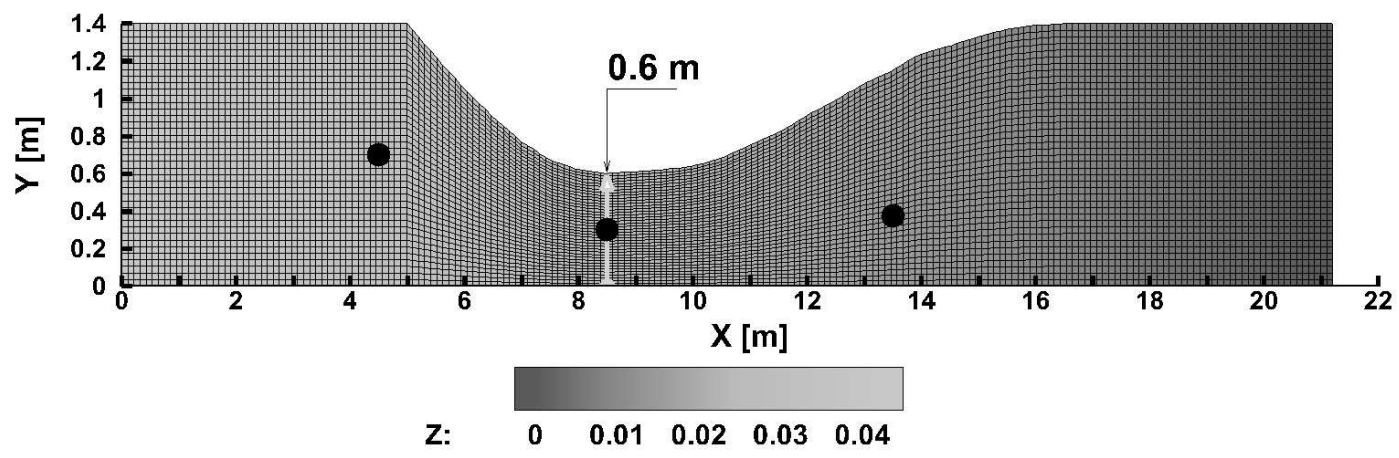

FIG. 2. Dam-Break in a convergent-divergent flume: Geometry of the channel, boundary-fitted grid, bathymetry and measurement points (black dots) 


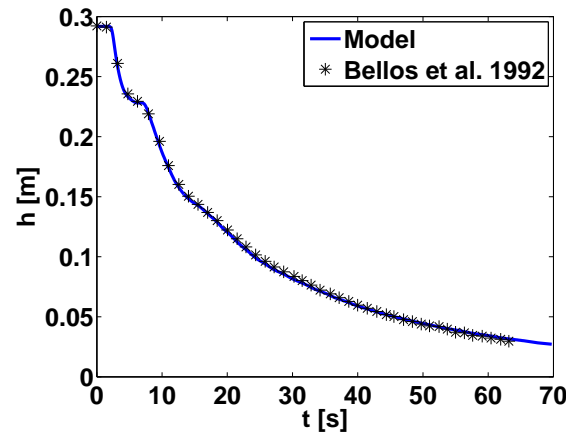

(a)

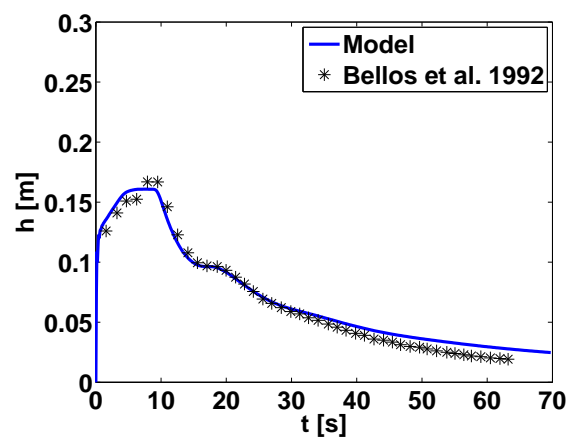

(c)

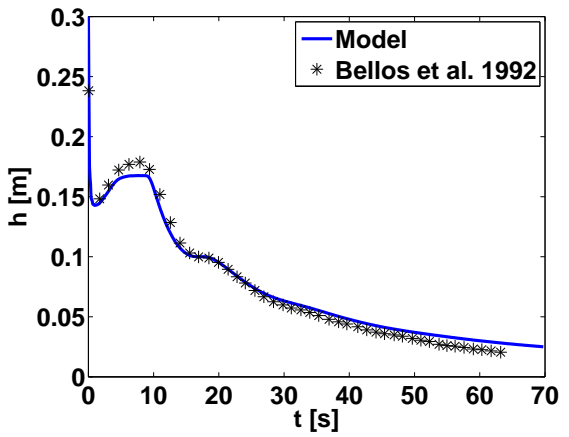

(b)

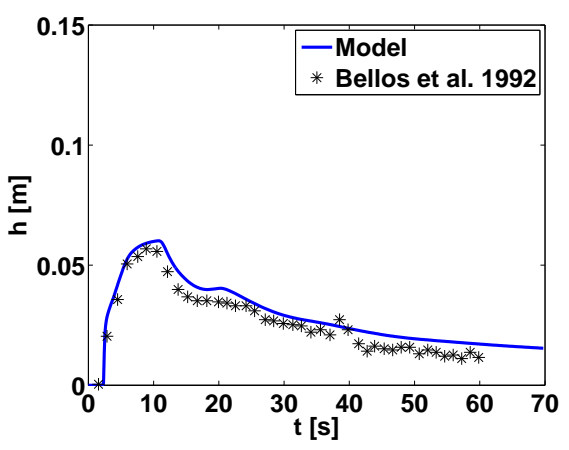

(d)

FIG. 3. Dam-Break in a convergent-divergent flume: Water depth time series at measurement points. (a) $\mathbf{x}=4.0 \mathrm{~m}$, (b) $\mathbf{x}=8.5^{-} \mathbf{m}$, (c) $\mathbf{x}=8.5^{+} \mathbf{m}$, (d) $\mathbf{x}=13.5 \mathrm{~m}$ 


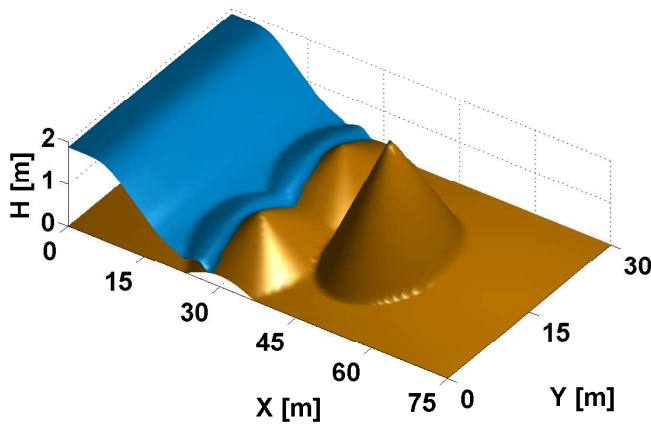

(a)

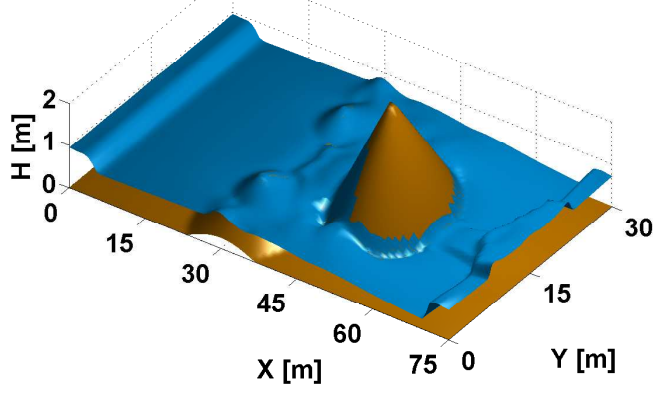

(c)

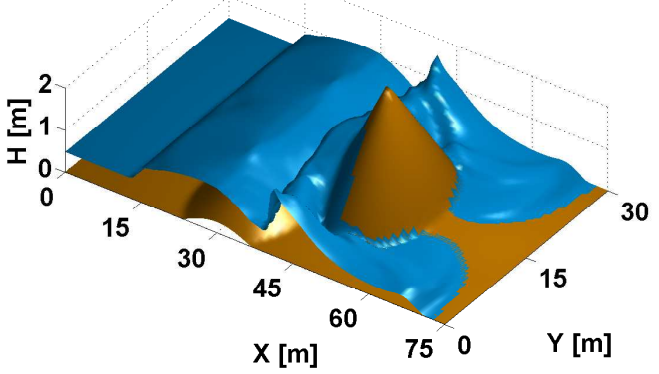

(b)

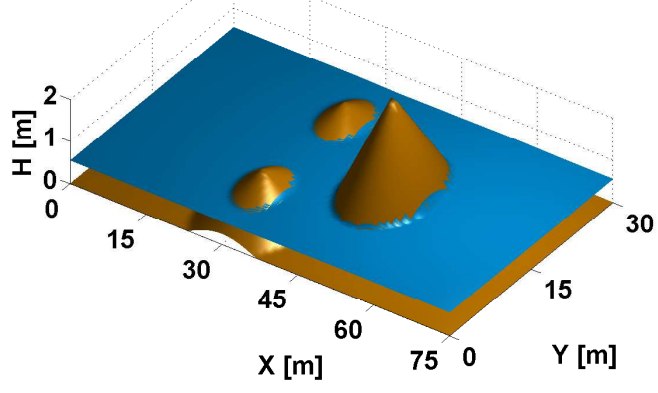

(d)

FIG. 4. Dam-Break over a closed basin: Free surface elevation. (a) $\mathbf{t}=2 \mathbf{s}$, (b) $\mathbf{t}=12$ $\mathbf{s},(\mathbf{c}) \mathbf{t}=20 \mathbf{s}, \mathbf{( d )} \mathbf{t}=300 \mathbf{s}$ 


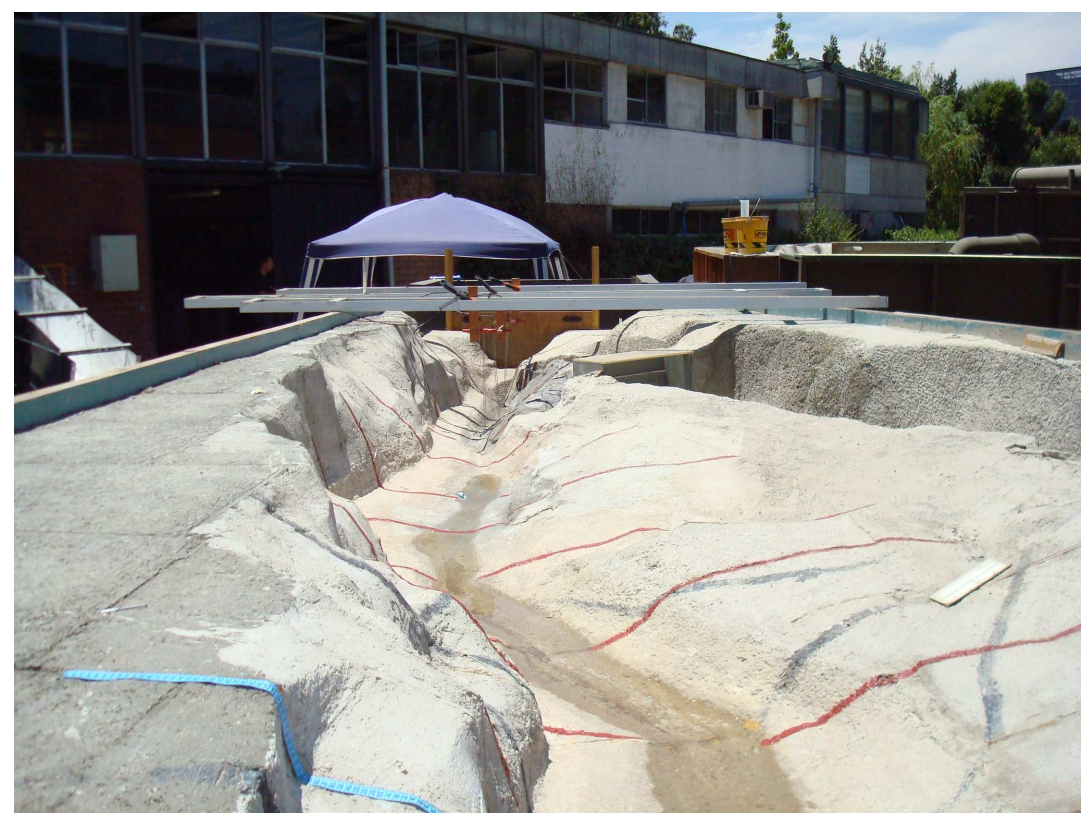

(a)

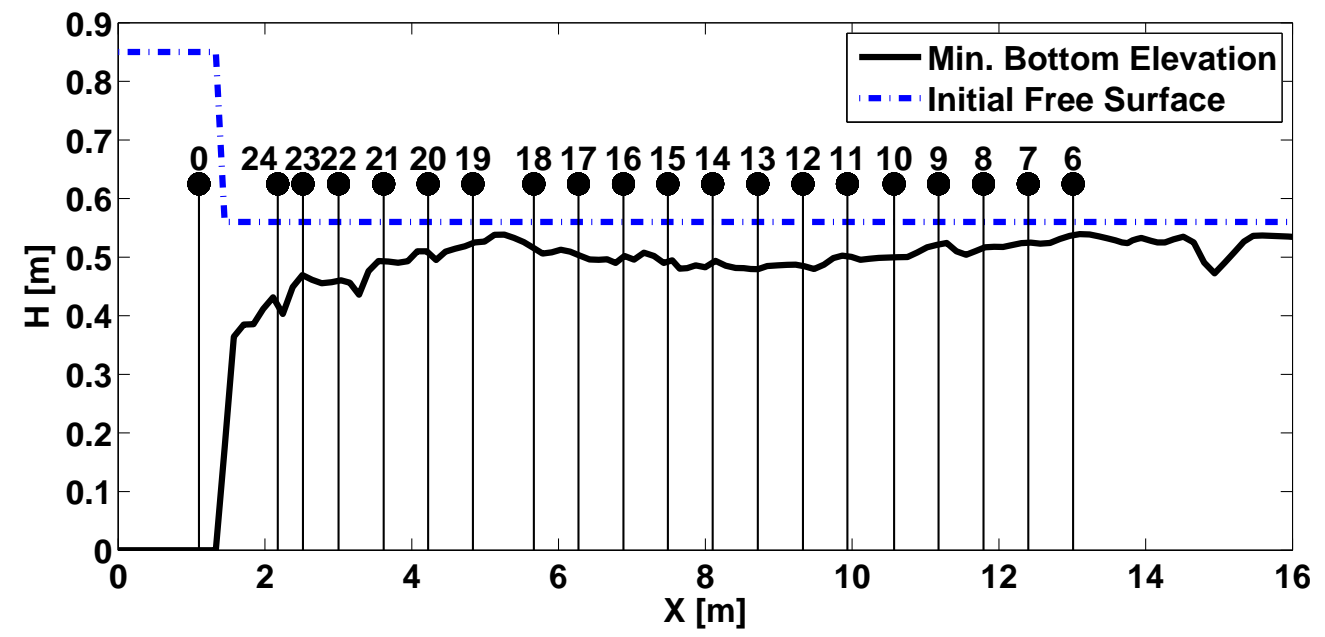

(b)

FIG. 5. Dam break Experience: (a) Physical model and measurement instruments, upstream view, (b) Longitudinal profile of the river reach bottom elevation, initial conditions and measurement points 


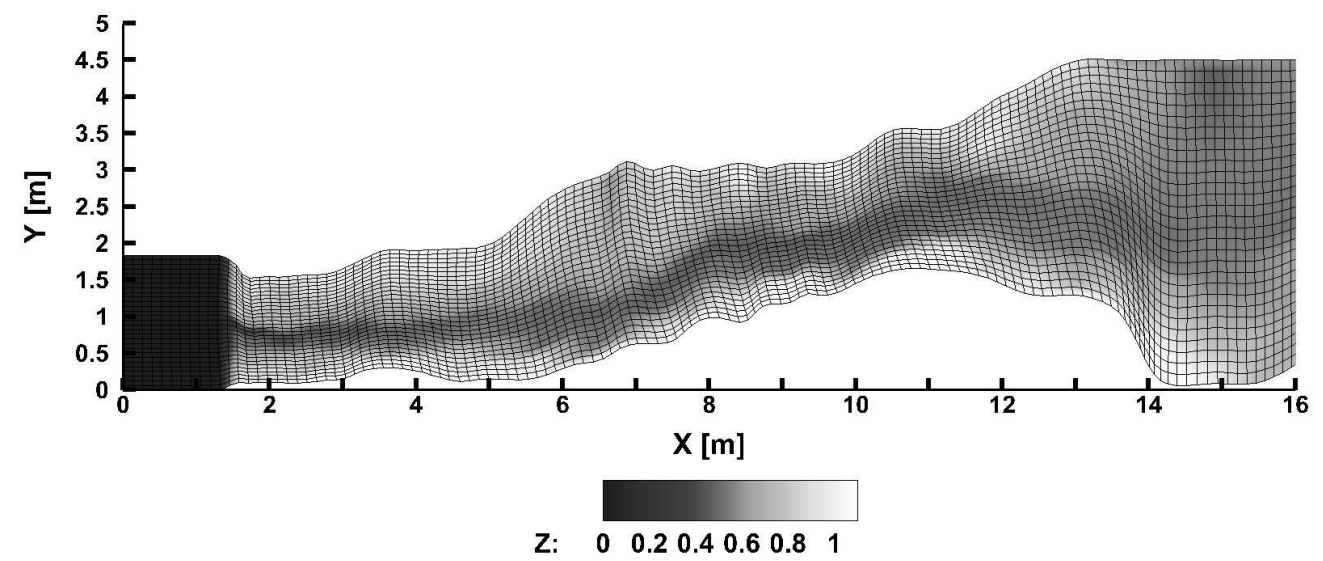

FIG. 6. Numerical Model of dam break experience: Digital bathymetry of the physical domain and curvilinear mesh of the physical model of $130 \times 30$ cells

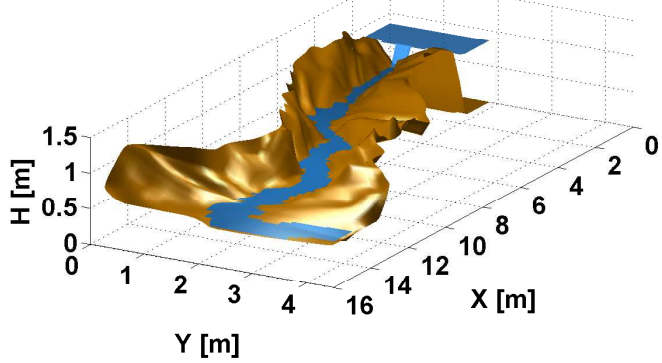

(a)

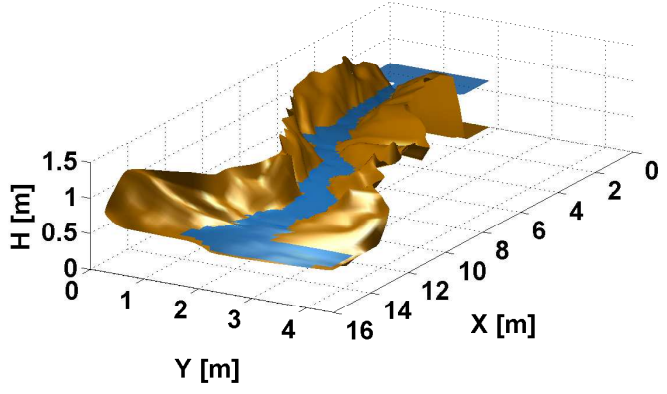

(c)

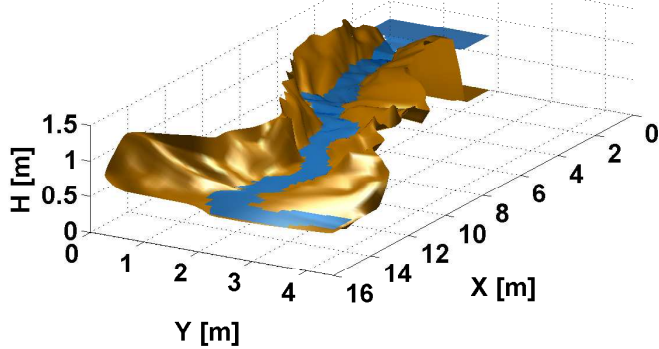

(b)

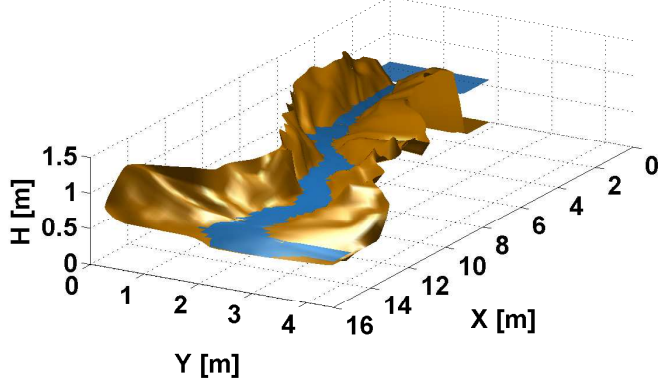

(d)

FIG. 7. Numerical model of dam-break experience: Flood extension at different times (a) Initial condition, (b) $t=4.4 \mathrm{~s}$, (c) $t=20 \mathrm{~s}$, (d) $t=60 \mathrm{~s}$ 


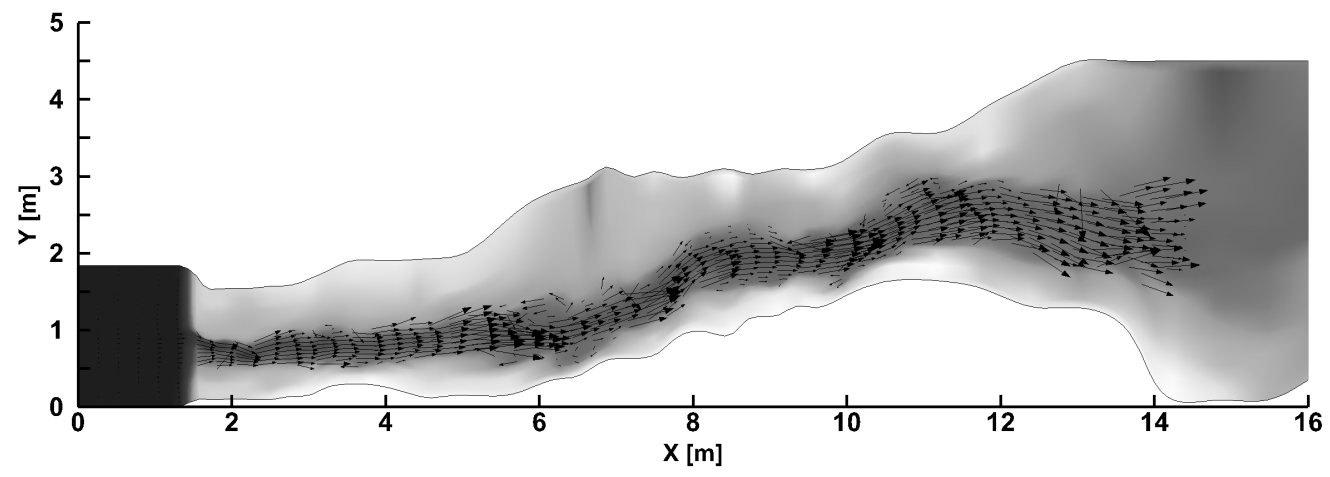

Z: $\quad \begin{array}{llllll}0 & 0.2 & 0.4 & 0.6 & 0.8 & 1\end{array}$
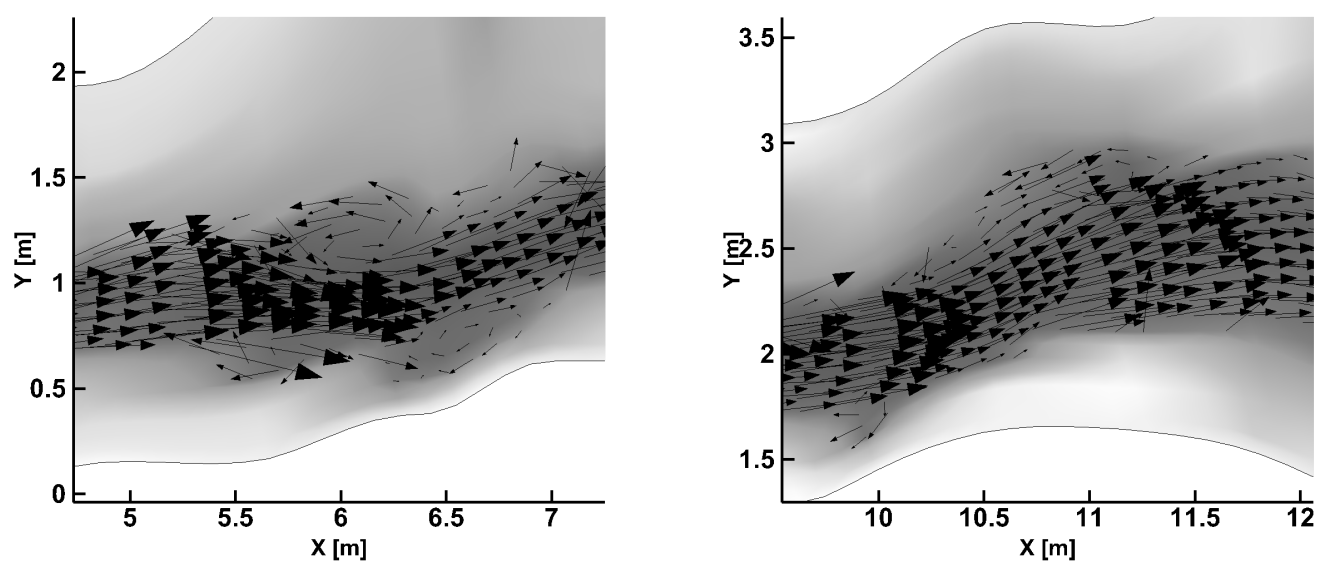

FIG. 8. Numerical model of dam-break experience: Velocity vectors for the propagation of the flooding wave over the river at $t=10 \mathrm{~s}$ 


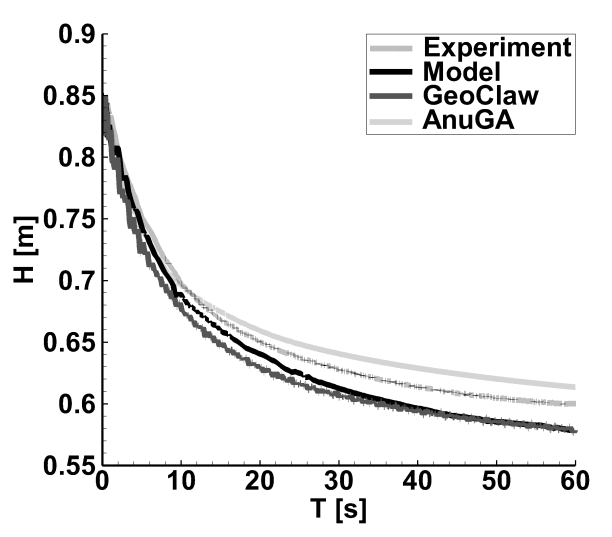

(a)

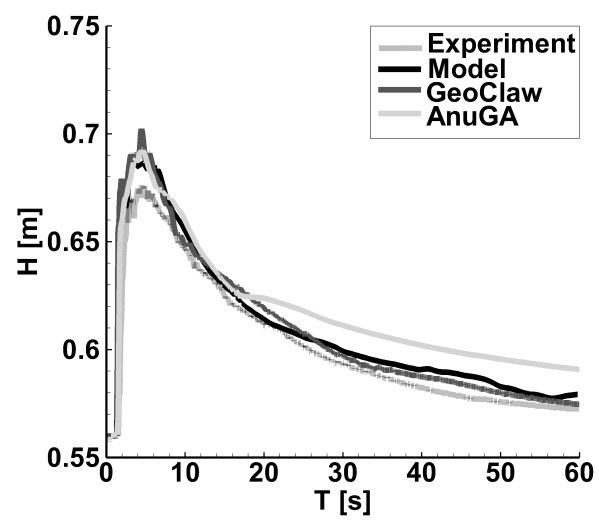

(c)

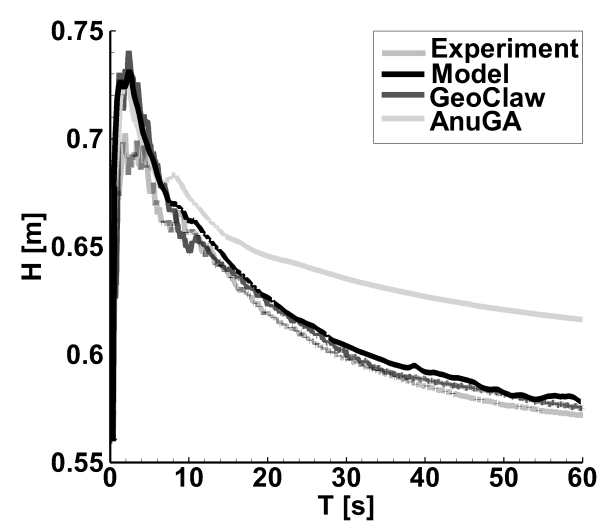

(b)

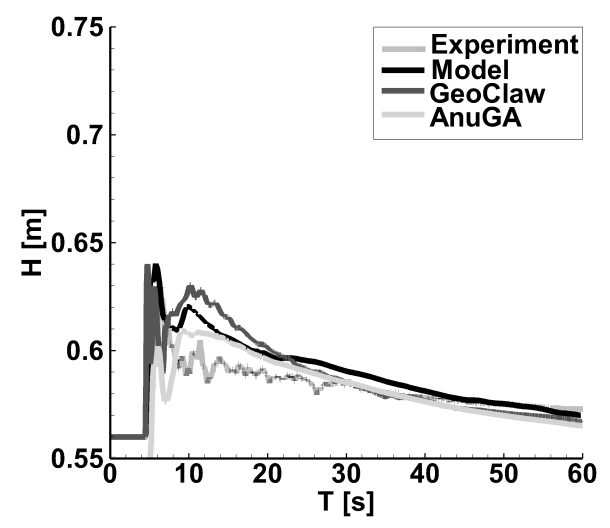

(d)

FIG. 9. Numerical model of dam-break experience: Comparison between measured and predicted free surface elevation at different locations, (a) Reservoir, (b) Gauge location 24, (c) Gauge location 20, (d) Gauge location 12. In all figures, the dotted black line represents the experiments and the solid lines represent the numerical results of our model, GeoClaw, AnuGA. 


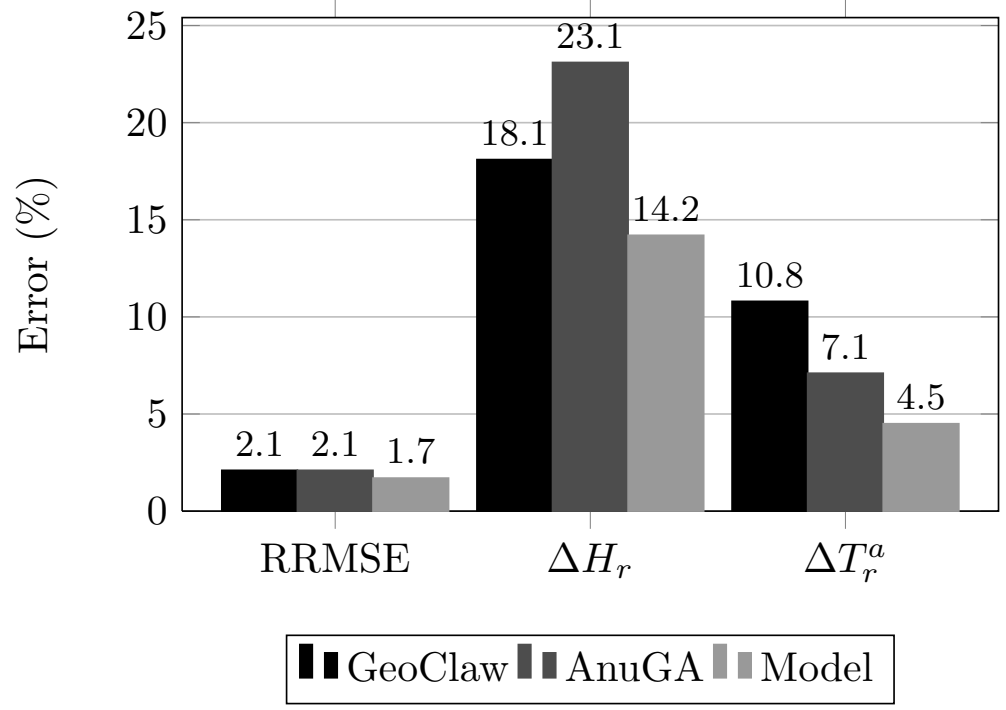

FIG. 10. Summary of mean relative errors between experiments and numerical results for each NSWE model. RRMSE: Relative root mean square error between experimental and numerical free surface elevation. $\Delta H_{r}$ Mean relative error in the maximum amplitude of the bore. $\Delta T_{r}^{a}$ : Mean relative error in the arrival time of the bore.

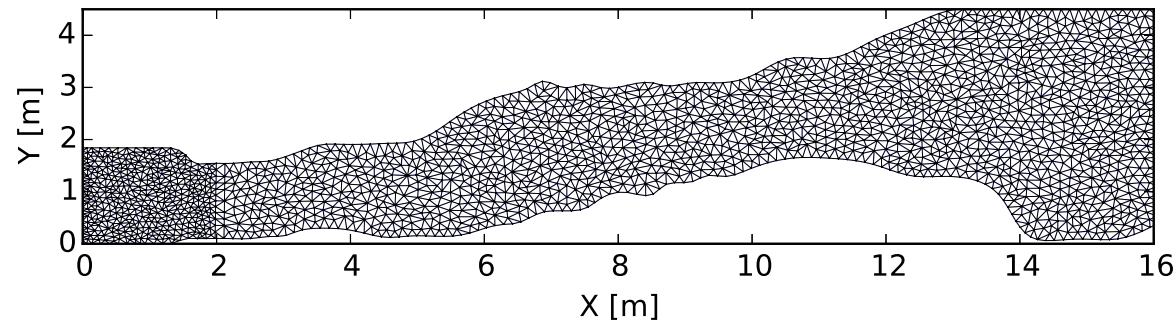

(a)

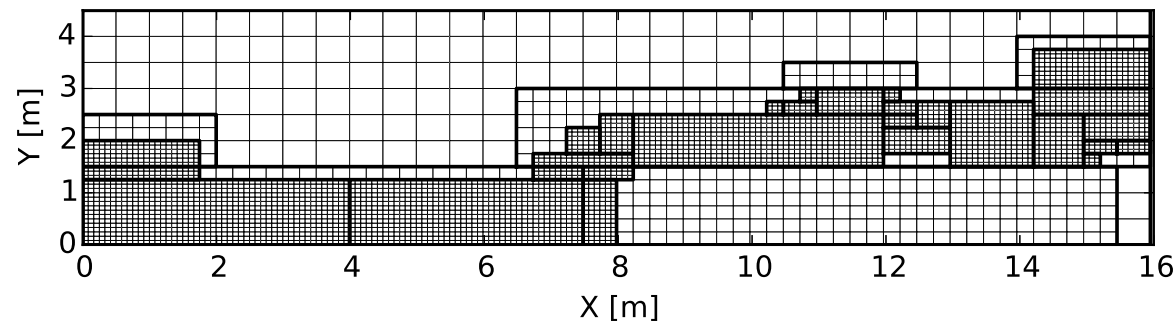

(b)

FIG. 11. Physical model discretization grids: (a) Triangular mesh of 4060 elements for AnuGA model, (b) Initial adaptive mesh with three levels of refinement for GeoClaw model 